\title{
Karl Polanyi y la hybris economicista de la Modernidad
}

\author{
Karl Polanyi and the economicist hybris \\ of Modernity \\ Jorge Polo Blanco \\ (Universidad Complutense de Madrid)
}

Recibido: 01/10/2012

Aceptado: 07/11/2012

\section{Resumen}

En este trabajo, y utilizando como eje la obra de Karl Polanyi, se intenta esbozar una crítica del economicismo y de la sociedad que lo produce, esa sociedad embarcada en un devenir histórico-cultural que bien puede comprenderse como una paulatina totalización económica de la vida humana. Ese es el recorrido crítico que aquí se quiere plantear, siquiera de manera embrionaria.

Palabras clave: Totalización económica, determinismo económico, economicismo.

\section{Abstract}

Using the work of Karl Polanyi as its axis, this study attempts to sketch a criticism of economicism and of the society that produces it, a society launched on a historical cultural path that may well be understood as a gradual economic totalization of human life. That is the critical path which will be posed here, if only in an embryonic manner.

Keywords: Economic totalization, economic determinism, economicism.

\section{La falacia económica}

Karl Polanyi constituye, sin duda, una figura que no se deja clasificar con facilidad en el ámbito de las ciencias sociales; podríamos decir, tal vez, que se trata de un historiador de la economía ciertamente heterodoxo, pero también un antropólo- 
go económico disidente. En cualquier caso sí podemos afirmar que estamos ante un referente esencial a la hora de elaborar una historia crítica del liberalismo económico y de la sociedad de mercado.

Hemos de comenzar diciendo que Polanyi disponía ya, evidentemente, de importantes elementos que contradecían ese paradigma dominante que se alzaba sobre los presupuestos de la naturalización y universalización del homo oeconomicus, y desde luego no podríamos dejar de mencionar en este contexto a influyentes figuras del pensamiento antropológico, tales como Marcel Mauss ${ }^{1}$ o Malinowski², que estaban ya sentando las bases para hacer añicos las concepciones dominantes sobre las "economías primitivas".

Algo que no pudo pasar desapercibido a Polanyi, en efecto, fue el decisivo hecho de que no existía, en semejantes sociedades arcaicas o neolíticas, una actividad económica desnuda, descarnada, explícita. Y lo que nosotros podríamos denominar, incurriendo en distorsionador anacronismo y extrapolación ilegítima, "intercambio económico", es una actividad que, como tal, no podía darse en tales órdenes sociales; esa presunta "actividad económica" aparece como algo que, en todo caso, nosotros podemos desprender analíticamente pero que en semejantes sociedades se da enteramente envuelta en otras actividades, por ejemplo de tipo mitológico o religioso, actividades que constituyen el verdadero sentido (normativo y consuetudinario) de dicha acción y dentro de las cuales aquélla se precipita de manera entretejida.

Por otro lado, y ahora en clave de polémica con la antropología marxista3, Polanyi también albergaría serias reticencias a la hora de admitir que las relaciones de parentesco, por poner un elemento paradigmático de los esquemas explicativos de las ciencias antropológicas, pudieran introducirse en la teorización asumiendo y jugando la función de relaciones de producción y, por lo tanto, aparecer como el elemento que determina en última instancia la reproducción del orden social. Pero en realidad el problema consiste en algo anterior, a saber: en determinar si existen, antes del surgimiento de la moderna economía de mercado, algo así como "relaciones de producción", esto es, algo que pueda legítimamente aislarse teóricamente como tal. Y el problema no se resuelve diciendo simplemente que en las sociedades premodernas las relaciones de parentesco, por ejemplo, funcionan como relaciones de producción ${ }^{4}$. El desciframiento materialista y economicista de toda la historia de las culturas humanas quedaría lastrado e impedido a la hora de comprender todo

\footnotetext{
1 Mauss, M.: Sociología y antropología, Tecnos, Madrid, 1991.

2 Malinowski, B.: Los argonautas del Pacífico occidental, Península, Barcelona, 1986.

3 En este sentido resulta muy interesante el trabajo del antropólogo marxista Maurice Godelier "Karl Polanyi y el lugar cambiante de la economía" que aparece en Lo ideal y lo material, Taurus, Madrid, 1990.

4 Ya Pierre Clastres arremetió contra esa antropología marxista que pretendía encajar categorías tales como "relaciones de producción" o "fuerzas productivas" en las sociedades arcaicas o primitivas.
} 
intercambio (entre los hombres y con la naturaleza) simbólico, gratuito, festivo, improductivo, o anti-utilitario 5 .

Resultaría muy interesante entender el planteamiento general de la obra polanyiana a través del tamiz de Thomas Kuhn. Lo decimos por lo siguiente: del mismo modo que en la historia de la ciencia, tras un cambio de paradigma, que en última instancia remite a un cambio de cosmovisión, los científicos ya no "ven" ni "habitan" el mismo mundo, pues lo que antes aparecía como formulable y problemático ahora, tras la mutación paradigmática, ya ni siquiera emerge como problema concebible (pues ni siquiera emerge, en general), de igual modo, decimos, la representación de lo económico en las culturas pre-capitalistas nada tiene que ver con lo que, dentro de la Weltanschauung capitalista, emerge con los contornos de lo económico.

En efecto, tras el advenimiento de la civilización capitalista los hombres empezaron a vivir en un mundo enteramente distinto, inmersos en fenómenos históricosociales inéditos de los que emergían determinados procesos que ahora comenzaban a ser vividos y percibidos como económicos, siendo esto último algo sencillamente inexperimentable e inidentificable en culturas y civilizaciones anteriores. Al respecto de lo cual decía Polanyi lo siguiente: "Hemos de desprendernos de la arraigada creencia de que la economía es un campo de actividad del que siempre han sido conscientes los seres humanos. Utilizando una metáfora, podemos decir que los hechos económicos estaban originariamente integrados en situaciones que no eran en sí mismas de naturaleza económica, pues ni los medios ni los fines eran esencialmente materiales. La cristalización del concepto de economía fue un fenómeno histórico, requirió tiempo"6. Una nueva realidad emergía, una nueva dimensión de la realidad histórico-cultural coagulaba con unos contornos marcadamente diferenciados, delimitados, desgajados de su vieja mezcolanza con otros nervios de lo social7.

Véase: "Los marxistas y su antropología", traducción de Mercedes Córdoba y Magro aparecida en la revista Vuelta, 122, 1987, pp. 10-15.

$5 \mathrm{Al}$ respecto de este amplio tema resulta muy recomendable la obra de Jean Baudrillard El espejo de la producción, Gedisa, Barcelona, 2000. También puede verse la obra de Georges Bataille: La parte maldita. Icaria, Barcelona, 1987. O también el libro de André Gorz Metamorfosis del trabajo, búsqueda del sentido; crítica de la razón económica, Sistema, Madrid, 1997.

6 Polanyi, K.: Comercio y mercado en los imperios antiguos, Labor, Barcelona, 1976, p. 288

${ }^{7}$ Así lo expresaría algún tiempo después Louis Dumont, discípulo de Karl Polanyi: "La era moderna ha sido testigo de la emergencia de un nuevo modo de considerar los fenómenos humanos y de la delimitación de un dominio separado que evocamos corrientemente con las palabras economía, económico. ¿Cómo ha aparecido esta nueva categoría, que constituye al mismo tiempo un compartimiento separado en la mentalidad moderna y un continente abierto a una disciplina científica, y a la que el mundo moderno atribuye en apariencia un gran valor?". Homo aequalis. Génesis y apogeo de la ideología económica, Madrid, Taurus, 1999, p.45. En efecto, el surgimiento de esta ideología económica desemboca en la emancipación del punto de vista económico como algo separado, como algo que se encierra en una disciplina de conocimiento escindida y autónoma, como algo que se deslinda del punto de vista 
El enfoque de Polanyi es institucional ${ }^{8}$, y por ello mismo diametralmente opuesto a todos aquellos enfoques socioeconómicos que se fundamentan en el individualismo metodológico, por lo cual se ha de entender que si el móvil de la ganancia jamás fue la norma generalizada en el comportamiento económico de las sociedades ajenas a la economía de mercado ello se debió, precisamente, a que dicha normatividad jamás fue instituida o institucionalizada en ninguna sociedad anterior a la civilización occidental decimonónica.

Lo que Polanyi jamás negó es que en culturas anteriores hubieran existido "elementos de mercado"; lo que niega es que haya habido con anterioridad alguna otra civilización en la que dichos elementos hayan quedado cohesionados en un sistema integral de mercado. Dice: "Un mercado autorregulado requiere nada menos que la separación institucional de la sociedad en una esfera económica y una esfera política [...] Podría argüirse que la separación de las dos esferas se da en todo tipo de sociedad en todo momento. Pero tal inferencia se basaría en una falacia. Es cierto que no puede existir ninguna sociedad sin algún sistema de cierta clase que asegure el orden de la producción y distribución de bienes. Pero ello no implica la existencia de instituciones económicas separadas [...] Como hemos visto, ni bajo las condiciones tribales, ni feudales, ni mercantilistas, había un sistema económico separado de la sociedad. La sociedad del siglo XIX, en el que la actividad económica estaba aislada y se imputaba a una motivación claramente económica, constituyó en efecto una excepción singular [...] Tal patrón institucional sólo podría funcionar si la sociedad se subordina de algún modo a sus requerimientos. Una economía de mercado sólo puede existir en una sociedad de mercado"9. Y sólo una sociedad de mercado podía ser el lugar histórico dentro del cual emergiera un concepto puro de lo económico, porque allí donde las actividades a través de las cuales se garantiza el sustento de los miembros de la comunidad están espontáneamente integradas en todos los otros aspectos de la praxis social, ninguno de ellos aparece como específicamente económico: la producción y distribución de bienes materiales se ejecutaba mientras se llevaban a cabo otro tipo de acciones, de lo cual no puede dejar de inferirse que la intencionalidad conscientemente económica de una acción es algo que no puede tener cabida en una sociedad dentro de la cual no existe nada parecido a una esfera económica separada. No existe ningún momento, dentro de la vida social, en la que sus miembros encarnen una funcionalidad exclusivamente económica, lo cual equivale a decir que los individuos nunca son agentes puramente económicos.

político y moral. Cristaliza así un nuevo campo de fuerzas, un nuevo ámbito, un nuevo dominio de lo real que aparece ante la conciencia con sus propias leyes internas y con su coherencia inmanente.

8 En ese sentido, sería importante tener presente las obras del llamado "institucionalismo americano", en especial la obra de Thorstein B. Veblen. Creemos muy recomendable, en ese sentido, el trabajo de Margarita Barañano: "Veblen y el homo oeconomicus", Reis, No 61, 1993, pp. 145-172.

9 Polanyi, K.: La gran transformación. Fondo de Cultura Económica, México, 2003, p. 121. 
En la medida en que las acciones que tienen que ver con el sustento material del grupo social se encuentren integradas o empotradas (embedded) en otras relaciones e instituciones comunitarias de suyo no económicas, la funcionalidad del endoesqueleto económico siempre se encuentra subordinada al mantenimiento y reproducción de un tejido comunitario en el que precipita su sentido y su fin. La racionalidad del comportamiento se ajusta a la normatividad de las instituciones sociales, las cuales no siempre han prefigurado una norma de acción social basada en la maximización de las ganancias personales.

Karl Polanyi combatió la universalidad de los presupuestos de la teoría económica dominante, ante todo dos de ellos, a saber, el mito del "interés propio universal" y el mito de la "escasez universal". Es así, pues, que ni la maximización ni la escasez han sido las reglas que han determinado universalmente toda economía humana, como pretendían la antropología y la economía formalistas ${ }^{10}$, pues de hecho siempre ha habido otros apremios, políticos, estéticos o religiosos, que han catalizado la acción social de manera preponderante, siendo así que el apremio puramente económico instalado de manera total y omnipresente es un fenómeno exclusivamente moderno, propio de una sociedad institucionalmente reducida a mercado y en la cual, y sólo en ella, aparecen sujetos económicos atómicos ${ }^{11}$. El sujeto configurado a través del "individualismo posesivo", por utilizar la expresión de Macpherson, es un producto histórico decantado en las modernas sociedades europeas, y no el arquetipo de toda subjetividad humana concebible12.

La escasez adquiría en las formulaciones económicas liberales un estatuto casi ontológico u ontopraxeológico, radicado en la esencia misma de todo comportamiento humano. Se postula como origen mismo de toda economía humana un conjunto de individuos-átomos espoleados por una cantidad de necesidades siempre infinita con respecto a la siempre limitada cantidad de bienes que pueden satisfacerlas ${ }^{13}$. Así, la eterna insatisfacción provocada por la sempiterna escasez anidaría en la raíz más profunda del movimiento económico de los hombres, derivándose de ello la necesidad del egoísmo y de la competencia14.

Las concepciones económicas basadas en la teoría subjetiva del valor, en sus formulaciones marginalistas y neoclásicas, construirán su edificio teórico, por lo

\footnotetext{
10 Véase Kaplan: "La controversia formalistas-substantivistas de la antropología económica: reflexiones sobre sus amplias implicaciones", en Antropología y economía, Anagrama, Barcelona, 1976.

11 Elias, N.: La sociedad de los individuos, Península, Barcelona, 1990.

12 Macpherson, C. B: La teoría política del individualismo posesivo, Trotta, Madrid, 2005.

13 Para desmentir este postulado de la "eterna escasez" resulta imprescindible conocer la obra de Marshall Sahlins: Economía de la edad de piedra, Akal, Madrid, 1977.

14 Para acercarnos a una panorámica de la "antropología formalista" a la que se enfrenta Polanyi podemos acercarnos a las siguientes trabajos: Burling: "Teorías de maximización y el estudio de la antropología económica”, en Antropología y economía, (Godelier), Anagrama, Barcelona, 1976. También puede verse, en ese mismo volumen, Leclair: "Teoría económica y antropología económica".
} 
tanto, sobre dos presupuestos medulares: la escasez y la elección ${ }^{15}$. La primera de estas dos categorías, la escasez, se concibe como un principio ordenador de todo comportamiento humano, lo cual se fundamenta a su vez en la presuposición de que las necesidades del hombre son ilimitadas. La combinación de esas ilimitadas necesidades junto con la premisa de la escasez de recursos hace de la elección un principio siempre presente en la acción humana. En ese juego categorial todos los elementos aparecen correlacionados y retroalimentan su funcionalidad semántica en un circuito cerrado.

Para desmontar todo ese conglomerado analítico, al menos en lo que a sus pretensiones de aplicabilidad universal se refiere, es necesario escapar de su gramática de presupuestos implícitos y, en todo caso, acudir, por ejemplo, a la historia comparada de los sistemas económicos o a la etnografía para desmentir ese ensamblaje de premisas aceptadas acríticamente. En ese sentido, podemos escuchar al citado Marcel Mauss: "Son nuestras sociedades occidentales las que han hecho, muy recientemente, del hombre un "animal económico", pero todavía no somos todos seres de este tipo (...) El homo economicus no es nuestro antepasado, es nuestro porvenir (...) El hombre, durante mucho tiempo, ha sido otra cosa. Hace sólo poco tiempo que es una máquina, una máquina complicada de calcular"16. Karl Polanyi se enfrentará a todo ese universo teórico acudiendo al desmontaje de sus supuestos implícitos.

En su estudio sobre las concepciones aristotélicas de lo económico, Polanyi se percata de que Aristóteles piensa y escribe, en cierta manera, desde una posición de reacción ante los procesos de mayor comercialización y especialización del trabajo que se estaban dando en la Atenas de su época; se podría descubrir en él un cierto miedo a que dichos procesos acaben produciendo una tendencia disolvente en la comunidad de ciudadanos (koinonía ton politon). El intercambio comercial, por lo tanto, debía estar sometido siempre al mantenimiento y recurrencia de esa comunidad política, y por eso mismo, una actividad comercial desatada y desmedida que escapara de esos límites y se dedicara a la pura ganancia, al intercambio que sólo persigue el mero incremento del beneficio, podría suponer una corrosión de los lazos comunitarios propios de la economía doméstica ${ }^{17}$.

\footnotetext{
15 Hemos de mencionar aquí obras emblemáticas dentro de esta concepción: Walras: Elementos de economía politica pura, Alianza, Madrid, 1987; Jevons: La Teoría de la Economía Política, Pirámide, Madrid, 1998; Pareto: Manual de Economía Política, Atalaya, Buenos Aires, 1945; Robbins: Ensayo sobre la naturaleza y significación de la ciencia económica. Fondo de Cultura Económica, México, 1980.

16 Mauss, M.: Sociología y antropología, Tecnos, Madrid, 1991, p. 256.

17 Véase Basañez, F.: "Entre la teoría económica y la economía política: estudio sobre Ética a Nicómaco V.5 y Política I.8-10, de Aristóteles. La filosofía económica de Aristóteles", Thémata. Revista de Filosofía, Sevilla, Número 13, 1995, pp. 37-72.
} 
Para el filósofo griego existían dos formas de intercambio, de las cuales sólo una de ellas era "conforme a la naturaleza", a saber, aquella cuyo fin no es el puro incremento de la riqueza. Ambas utilizan la propiedad y los bienes, pero no de la misma manera ${ }^{18}$. Y es ahí donde aparece la hybris, el gran exceso de la compraventa encaminada exclusivamente al lucro, el exceso antinatural de los que dedican todo su tiempo y su quehacer al negocio y a la obtención del beneficio, supeditando a esa tarea todas las facultades del hombre, que pierden por ello toda su nobleza, toda su virtud ${ }^{19}$. Es el deseo ilimitado de la ganancia por sí misma el que sobrepasa el intercambio virtuoso sometido a las normas encaminadas al mero sostén de la economía doméstica ${ }^{20}$.

En este contexto, Karl Polanyi insiste en la "solidaridad tribal" de las comunidades arcaicas, las cuales se desenvuelven con un marcado principio interno de reciprocidad en el que la fortificación de los lazos comunes se muestra como el principio rector de la vida social21. En ese sentido, dentro de estas formas arcaicas no puede permitirse la existencia sistemática y prolongada de ninguna forma disgregadora de actividad que persiga el puro enriquecimiento económico individual al margen de dichos lazos comunitarios.

18 Aristóteles: Política I, $1257 \mathrm{~b} 15$.

19 Eso que Aristóteles denunciara como peligrosamente antinatural se corresponde, en buena medida, a lo que Marx denominaría propiamente "circulación de capital", por contraposición a aquella "circulación simple de mercancías". Dicha circulación, que corresponde a la crematística aristotélica, es un movimiento siempre ilimitado cuya finalidad, como hemos visto, no es el incremento del valor de uso sino el aumento cuantitativo que sólo pone en juego el valor de cambio. Y la finalidad del capital, en su movimiento inherentemente ilimitado, es siempre él mismo, su crecimiento, su propia revalorización. Así lo expresan Fernández Liria y Alegre: “[...] en la sociedad capitalista, cuando el fin de todo el proceso no es la producción de algún valor de uso, sino la valorización de alguna inversión inicial, nos encontramos, en primer lugar, con que se trata de un proceso que no puede conocer término alguno. Si el centro de gravedad del proceso lo ocupa el trabajo, es posible descansar cuando la utilidad está cubierta. Sin embargo, si el objetivo que rige el proceso de producción es la valorización de un capital adelantado, entonces nos movemos ya en un ciclo en el que el capital sólo persigue producir más capital, en un proceso sin fin”. El orden de El Capital, Akal, Madrid, 2010, p.360. El capital sólo produce más capital. Evidentemente el ciclo D-M-D' de la antigua Grecia no es comparable con el de la Inglaterra decimonónica. En ese sentido, Polanyi se opone a las interpretaciones "modernizadoras" de la vida económica de la Antigüedad, en la cual creían ver el desarrollo de algo parecido a un "capitalismo antiguo" (Meyer, Rostovtzeff) Pero, en cualquier caso, Polanyi puede descubrir en Aristóteles la denuncia de esa hybris que, si bien el Estagirita podía vislumbrar sólo como un peligro potencial o embrionario, en la moderna sociedad capitalista aparece ya como un proceso acuciante y definitorio. 20 Maucourant, J.: Descubrir a Polanyi, Bellaterra, Barcelona, 2006.

21 No podemos dejar de mencionar, aunque no hay cabida en este trabajo para su desarrollo, las concepciones polanyianas en torno a las tres formas básicas de integración. Las modalidades concretas de institucionalización de la economía se explicitan mediante el estudio de las formas de integración. Cada una de las tres formas manejadas por Polanyi, esto es, reciprocidad, redistribución e intercambio, se encarnan a su vez en unas estructuras de apoyo que, respectivamente, vienen definidas por la simetría, la centralización y el mercado. 
La obra póstuma de Polanyi, The livelihood of Man, aparecida en 1977, comienza con una crítica frontal a esa mentalidad de mercado que se erige en el principal obstáculo a la hora de comprender, por un lado, la historia de las civilizaciones humanas $\mathrm{y}$, por otro, la verdadera situación en la que se encuentra el hombre contemporáneo. Dicha mentalidad se infiltra insidiosamente en el sentido común de una época y además contamina buena parte de campos enteros del conocimiento tales como son la historia económica, la antropología, la sociología o la psicología.

Las ciencias humanas, en suma, acaban siendo atravesadas por esa "mentalidad de mercado" que llega a convertirse, de igual modo, en la fantasía generalizada de toda una época. "Casi nunca es pertinente resumir la ilusión general de una época en términos de error lógico; aunque, conceptualmente, la falacia económica, no puede describirse de otra manera [...] Es decir, el error estuvo en igualar la economía humana general con su forma de mercado [...] La falacia es evidente en sí misma: el aspecto físico de las necesidades del hombre forma parte de la condición humana; ninguna sociedad puede existir si no posee algún tipo substantivo de economía. Por otra parte, el mecanismo oferta-demanda-precio (al que popularmente se denomina mercado), es una institución relativamente moderna con una estructura específica, que no resulta fácil de establecer ni de mantener. Reducir la esfera del género económico, específicamente, a los fenómenos del mercado es borrar de la escena la mayor parte de la historia del hombre." 22 Como podemos ver en este texto, se entrecruzan dos nociones en torno al problema de la falacia económica. En efecto, dicha falacia constituye un elemento importante de la "ilusión general de una época" y, a la vez, un error lógico y teórico del discurso dominante en las ciencias sociales. Por supuesto, ambos aspectos son indistinguibles en tanto en cuanto aquella visión de lo que es y significa la actividad económica del hombre aparece instalada tanto en eso que podemos denominar "imaginario colectivo" o "filosofía moral de una época" como en el armazón conceptual de las teorías socioeconómicas.

El combate polanyiano contra dicha falacia económica debe inscribirse principalmente en un intento de quebrar ese imaginario cerrado que no puede postular otras formas alternativas de organizar socialmente el sustento material de los hombres, distintas a la forma en la que lo hace la economía de mercado 23 . Luego volveremos sobre esto, al concluir este trabajo.

La llamada tríada cataláctica, esto es, comercio, mercado y dinero, no había formado, hasta la llegada inédita de la economía de mercado, un sistema unitario e integrado. Polanyi establece que esa unidad en un mismo sistema no podía encontrarse en ninguna sociedad distinta a la moderna sociedad capitalista24. "Esta pro-

\footnotetext{
22 Polanyi, K.: El sustento del hombre, Biblioteca Mondadori, Madrid, 1994, p. 77.

${ }^{23}$ Lahera Sánchez, A.: "La crítica de la economía de mercado en Karl Polanyi: el análisis institucional como pensamiento para la acción", Reis, número 86, 1999 pp. 27-54.

24 Moreno Feliu, P.: El bosque de las Gracias y sus pasatiempos. Raíces de la antropología económica, Trotta, Madrid, 2011.
} 
blemática cuestión se eludió en todas las investigaciones específicas por la presunción tradicional de que comercio, dinero y mercados estaban indisolublemente unidos. Donde había comercio, se daba por sentada la existencia de mercados, y donde había dinero, se suponía la existencia de mercados, y por tanto del comercio. En realidad, en la mayor parte de la historia económica, se deberían contemplar por separado el origen del comercio, los usos del dinero y los elementos de mercado" 25. Polanyi se emplea en deshacer el gran equívoco que consiste en considerar que comercio, dinero y mercado se encuentran indisolublemente unidos, tanto desde un punto de vista lógico-teórico como histórico-empírico. En efecto, la historia económica nos muestra la no co-implicación necesaria de esos elementos, co-implicación que la teoría económica liberal querría ver como dada desde siempre en la historia de la humanidad, siendo así que esos tres elementos tienen desde un punto de vista histórico-empírico orígenes distintos, y su integración correlativa en un sistema homogéneo y funcionalmente integrado sólo empieza a darse en otro momento histórico, en la moderna sociedad de mercado.

\section{El "molino satánico"}

La noción de doble movimiento es de una importancia capital a la hora de acercarnos a la comprensión polanyiana del desarrollo histórico de la civilización liberal decimonónica. La podemos encontrar sintetizada en el siguiente pasaje: "La historia del siglo XIX fue así el resultado de un movimiento doble [...] Mientras que la organización de los mercados mundiales de mercancías, los mercados mundiales de capital y los mercados mundiales de dinero daba un impulso nunca antes visto al mecanismo de los mercados bajo la égida del patrón oro, surgía al mismo tiempo un movimiento profundamente arraigado para resistir los perniciosos efectos de una economía controlada por el mercado. La sociedad se protegía contra los peligros inherentes a un sistema de mercado autorregulado" 26 . En ese sentido, Polanyi resalta que, en un primer momento, fueron las fuerzas reaccionarias de la sociedad las que se opusieron a la libre mercantilización de la tierra y a la configuración de un mercado libre de mano de obra. De igual modo pueden encontrarse distintos procesos de resistencia popular y consuetudinaria a los procesos de secularización mercanti127.

También fue la lucha sindical embrionaria, y ulteriormente un movimiento obrero cada vez más poderoso, el que hubo de intervenir para detener esa corrosión nihilista de todos los mimbres antropológicos y ello, en cierta medida, a pesar de

\footnotetext{
25 Polanyi, K.: El sustento del hombre, Mondadori, Barcelona, 1994, p. 157.

26 Polanyi, K.: La gran transformación, Fondo de Cultura Económica, México, 2003, p. 127.

27 Thompson, E. P.: Costumbres en común, Barcelona, Crítica, 1995.
} 
que las reivindicaciones obreras estuvieran muchas veces reducidas a meros incrementos cuantitativos de salario y su lucha fuera en muchas ocasiones, por ello, también puramente económica. Dicho problema reaparecerá más adelante. A pesar de lo cual, decimos, el movimiento obrero, con mayor o menor consciencia de ello, también batalló contra ese proceso de corrosión y disolución de los lazos antropológicos extra-económicos. "Fue necesaria la intervención exterior de la lucha sindical para recordar a la lógica del capital que no podía permitirse el lujo de superar al ser humano más allá de ciertos límites: la sociedad capitalista necesitaba seguir siendo sociedad, aunque fuese de manera muy periférica." 28 . Se trataba, en ese sentido, de que el Derecho impusiera coactivamente unos límites a la voracidad ilimitada del capital en cuanto a su apropiación de la fuerza de trabajo se refiere, esto es, de imponer unos límites a esa hybris inherente al capital que, dejado a su libre desenvolvimiento, tendería en el límite a apropiarse del trabajo humano durante las veinticuatro horas del día.

Hay algún texto muy elocuente de Karl Polanyi en el que se destaca que la labor del Parlamento fue siempre la de promover un mercado de trabajo enteramente libre en el cual la mercancía-trabajo estuviese plenamente disponible para alcanzar su precio de mercado, lo cual no podía conseguirse sino imposibilitando por todos los medios la entrada del movimiento obrero en la configuración del Derecho. "En Inglaterra se convirtió en Ley no escrita de la Constitución que debía negarse el voto a la clase trabajadora. Los líderes cartistas fueron encarcelados [...] Los cartistas habían luchado por el derecho a detener el molino del mercado que aplastaba la vida de la gente. Pero se otorgaron derechos a la gente sólo cuando ya se había realizado el horrible ajuste. Dentro y fuera de Inglaterra, desde Macaulay hasta Mises, desde Spencer hasta Sumner, no había ningún liberal militante que no expresara su convicción de que la democracia popular era un peligro para el capitalismo"29. Cuando las condiciones estaban creadas para configurar un mercado laboral enteramente libre, tras una secular intervención estatal y gubernamental, en ese momento, ya sí, el papel del Parlamento era velar por la espontaneidad funcional del mercado formador de precios, especialmente para esa mercancía tan especial llamada "trabajo humano". Ahora sí, el papel de las leyes tenía que ser impedir, por ejemplo, un derecho a huelga que habría impedido a las fuerzas del mercado configurar un precio adecuado y óptimo, "natural", para la mercancía-trabajo.

Pero la comprensión puramente económica de los procesos histórico-culturales, en efecto, haciendo excesivo hincapié en el fenómeno de la mera explotación económica (que por otra parte Polanyi nunca niega) soslaya empero y deja fuera del foco comprensivo el fenómeno más amplio de la desintegración cultural ${ }^{30}$. ¿Desde

\footnotetext{
${ }_{28}$ Fernández Liria, C.; Alba Rico, S.: El naufragio del hombre, Hiru, Hondarribia, 2010, p. 114.

29 Polanyi, K.: La gran transformación. Fondo de Cultura Económica, México, 2003, p. 286.

30 Dalton, G.: Sistemas económicos y sociedad, Alianza, Madrid, 1974.
} 
qué parámetros puede la historiografía liberal aseverar que dicha transición hacia una economía de tipo industrial supuso, a largo plazo, un mejoramiento de la vida de la gente común? Desde unos parámetros y unos índices meramente económi$\cos ^{31}$ : los indicadores de los salarios y la tasa de crecimiento demográfico suponen parámetros objetivos, dicen, desde los cuales evaluar y juzgar un determinado proceso histórico y a la hora de determinar su calidad de progreso. Y, por otra parte, desde una perspectiva marxista, o desde un "marxismo vulgarizado" 32 , ¿qué parámetro ha de ser utilizado a la hora de juzgar y evaluar el grado de destrucción y sufrimiento padecidos por la población trabajadora dentro del nuevo marco del modo de producción capitalista? La tasa de explotación económica y la cantidad de plusvalor extraído de la fuerza de trabajo durante la jornada laboral podrían guiar, en este caso, la respuesta.

Podría decirse que Polanyi acusaba a los marxistas de haber concedido a sus enemigos liberales un importante elemento: a saber, el hecho de determinar y medir en términos puramente económicos el proceso histórico en cuestión. Cuando Karl Polanyi hace suyas las conceptualizaciones que Robert Owen proponía para comprender de manera cabal lo que supuso para los trabajadores el tránsito hacia un modo de vida enteramente distinto, a saber, ese modo de vida troquelado en los fuegos de la industrial capitalista, estaba tratando de hacer emerger todo aquello que escaparía a nuestra aprehensión si nos limitásemos a contemplar el fenómeno solamente desde el punto de vista de los salarios o de los ingresos monetarios.

Polanyi reconocía abiertamente su deuda con el socialista inglés: "También aquí calaba hondo Owen, destacando la degradación y la miseria, no los ingresos. Y como causa primordial de esta degradación señalaba correctamente a la dependencia de la fábrica en lo referente a la mera subsistencia. Entendía que lo que aparecía primordialmente como un problema económico era esencialmente un problema social. En términos económicos, el trabajador estaba siendo ciertamente explotado: no recibía en el intercambio lo que le correspondía. Esto era importante, pero no era todo. A pesar de la explotación, el trabajador podría haber estado mejor que antes en términos financieros. Pero un principio muy desfavorable para la felicidad individual y general estaba destruyendo su ambiente social, su vecindad, su posición dentro de la comunidad, su oficio [...] La Revolución Industrial estaba provocando una dislocación social de enormes proporciones, y el problema de la pobreza era sólo el aspecto económico de este evento." 33 La explotación no era sólo un aspecto salarial, ya que la pobreza bestial que estaba mermando las condiciones de vida

\footnotetext{
31 En este punto resulta imprescindible mencionar la obra de Amartya Sen; véase, por ejemplo, Desarrollo y libertad, Editorial Planeta Argentina, Buenos Aires, 2000. También, La calidad de vida, Fondo de Cultura Económica, México, 1993.

32 Hobsbawm, E.: Marxismo e historia social, Universidad Autónoma de Puebla, México, 1983.

33 Ibíd. p. 184
} 
de millones de personas no podría solventarse o disiparse con un mero incremento de dicho salario, pues el empobrecimiento suponía una desintegración social y moral del ambiente familiar y social de dichas Comunidades.

Polanyi parece referirse a los marxistas cuando concede la existencia, desde luego no desdeñable, de un intercambio desigual entre patrono y trabajador. Pero destaca a renglón seguido que la penuria de ese mismo trabajador no se reduce, sólo, a dicha desigualdad. Del mismo modo arremete contra el "credo liberal" que sostiene, por las mismas razones, que una mejora en los salarios de las capas trabajadoras supone, de manera automática, un progreso y una mejora indiscutible en la vida de dichas poblaciones, siendo así que la "habitación" de los hombres en su mundo se contemplaría sólo bajo las coordenadas de un nivel de vida computado desde lo econométrico.

Aquello que la obra polanyiana trata de mostrar es algo que bien podría definirse con las palabras de profesor Fuentes Ortega, a saber: una "reducción económica abstracta de la vida" 34 . Advierte Polanyi que ese vacío cultural no puede ser compensado con una vida limitada a la satisfacción de las necesidades económicas básicas. Una vida limitada al mero consumo económico, que ya no es el disfrute comunitario de lo socialmente producido, va quedando privada de toda dignidad. "Sin embargo, algunos de quienes convendrían plenamente en que la vida en un vacío cultural no es vida en absoluto parecen esperar que las necesidades económicas llenen automáticamente ese vacío y hagan aparecer a la vida digna de ser vivida bajo cualesquiera condiciones. Este supuesto se ve claramente refutado por el resultado de la investigación antropológica"35. En este texto resuena, de alguna manera, aquél en el que Marx hablaba del reino de la necesidad y del reino de la libertad ${ }^{36}$. En ese sentido, Polanyi no podría sino estar de acuerdo con ese pasaje de El Capital, ya que para el pensador austrohúngaro la vida digna de ser vivida es aquella que se da, efectivamente, más allá del reino de la pura necesidad material, más allá del puro intercambio metabólico y reductivamente económico con el entorno natural y con los otros hombres. El ser humano sólo aspira a una vida digna cuando no se limita meramente a sobrevivir y en tanto que puede sobrevivir socialmente sin limitarse con ello a la mera economización absoluta.

Creemos, por lo tanto, que el nervio más esencial del pensamiento polanyiano es aquél que se resiste a esa totalización económica de la vida humana que empezó a cristalizar en las sociedades industriales avanzadas ${ }^{37}$.

\footnotetext{
34 Fuentes Ortega, J. B.: La impostura freudiana, Madrid, Encuentro, 2009, p. 129.

35 Polanyi, K.: La gran transformación, Madrid, Fondo de Cultura Económica, México, 2003, p. 216. 36 Marx, K: El capital. Crítica de la economía política. Libro III, Tomo III, Akal, Madrid, 2000, p. 272. $37 \mathrm{He}$ tratado estos temas en otro lugar, a saber, en la obra Perfiles posmodernos. Algunas derivas del pensamiento contemporáneo, Madrid, Dykinson, 2010. En especial el capítulo 5, "Del productivismo moderno al consumo posmoderno del mundo" y el Apéndice 1, "El economicismo como marco último de comprensión de la realidad humana en la sociedad de (reducida a) mercado".
} 


\section{El economicismo como imagen del mundo}

El laissez-faire, médula constitutiva del credo liberal, no se desarrolla plenamente como doctrina y como principio organizativo de lo social hasta bien transcurridas las tres primeras décadas del siglo XIX, aunque semejante término se hubiera usado ya con anterioridad. Uno de los dogmas fundantes de la religión secular del laissez-faire consistía en concebir que el mercado autorregulado era el resultado natural de una evolución de las sociedades humanas que, dejadas a su sola espontaneidad, habrían de llegar siempre, y finalmente, a ese estadio final y definitivamente perfecto. Bajo semejante concepción, si tal mercado autorregulado no había aparecido antes en la historia había sido únicamente porque siempre había permanecido como una fuerza latente, como una tendencia soterrada, como una potencia inherente aunque conculcada por efecto de las interferencias administrativas, legislativas, gubernamentales. Polanyi se opone radicalmente a semejante presupuesto constitutivo del dogma liberal 38 .

El sistema de mercado autorregulado, el más inédito de los mecanismos institucionales y el más exótico de todos los sistemas económicos habidos en la historia de las culturas, no supone la evolución final de algo así como "la economía natural de los hombres"; Polanyi no puede asumir que dicho mercado autorregulado sea concebido como una tendencia natural por fin liberada en la espontaneidad de la historia occidental decimonónica sino que, muy al contrario, entiende que se introdujo artificialmente, y por cierto con mucha dosis de brutalidad y violencia, a través de la imposición del poder político y estatal ${ }^{39}$. Ese es el verdadero origen del laissezfaire, y Polanyi se ocupa bien de señalarlo. "El laissez-faire no tenía nada de natural; los mercados libres no podrían haber surgido jamás con sólo permitir que las cosas tomaran su curso." 40 Por lo tanto, la emergencia histórica de una sociedad de mercado, en el contexto de las modernas sociedades industriales, suponía la consagración de una visión del mundo que volcaba toda su fe secular en los principios del libre mercado autorregulado. Pero si la filosofía liberal predicaba que dicha "libertad de mercado" había emergido en la espontaneidad evolutiva de la historia, Polanyi advierte que los procesos de mercantilización de todos los ámbitos de la cultura humana supusieron un proceso histórico violento que poco tenía de "natural".

Lo que Polanyi denominara falacia económica y ficción mercantil, y que criticara como un gravísimo error metodológico y conceptual de la ciencia económica

\footnotetext{
38 Ludwig von Mises, máximo exponente de la Escuela Austriaca de Economía, contemporáneo y contrincante de Polanyi, se opone explícitamente a todos aquellos que afirman que el capitalismo no es más que un modelo de producción histórico y contingente. Véase su Teoría e historia, Unión Editorial, Madrid, 1974, p. 409.

39 Resulta ineludible aludir aquí al esencial capítulo "Acumulación originaria”, en Das Kapital, de Marx y Engels.

40 Polanyi, K.: La gran transformación. Fondo de Cultura Económica, México, 2003, p. 194.
} 
liberal, acabó empero efectuándose en la historia de las sociedades modernas o, al menos, empezó a efectuarse. Y es así como termina cobrando realidad el experimento utópico de la sociedad de mercado: "El mecanismo oferta-demanda-precio, cuya primera aparición dio origen al concepto profético de «ley económica», se convirtió rápidamente en una de las fuerzas más poderosas que jamás haya penetrado en el panorama humano. Al cabo de una generación -es decir, de 1815 a 1845 [...] el mercado formador de precios que anteriormente sólo existía como modelo en varios puertos comerciales y algunas bolsas, demostró su asombrosa capacidad para organizar a los seres humanos como si fueran simples cantidades de materias primas, y convertirlos, junto con la superficie de la madre tierra, que ahora podía ser comercializada, en unidades industriales bajo las órdenes de particulares especialmente interesados en comprar y vender para obtener beneficios. En un período extremadamente breve, la ficción mercantil aplicada al trabajo y a la tierra, transformó la esencia misma de la sociedad humana. Esta era la identificación de la economía y el mercado en la práctica"41. Empieza a cobrar sentido la expresión sociedad de mercado cuando, precisamente, en el orden social se produce una hipertrofia del aparato tecno-económico y cuando éste empieza a fagocitar todos los otros tejidos sociales de suyo no-económicos de los que previamente se había emancipado y desgajado para, como decimos, reabsorberlos en el fragor de su dinámica interna.

Sólo en dicho contexto podía emerger, por lo tanto, una visión del mundo y de la historia eminentemente economicista. Así concluye de nuevo el profesor Fuentes Ortega: "Se comprende entonces que las ideas más características o representativas de la nueva sociedad, y precisamente en cuanto que las ideas no son sólo un reflejo, índice o señal de los tiempos, sino también y muy especialmente un factor o ingrediente constitutivo esencial de los mismos, hayan venido contrayéndose significativamente en la dirección de reducirse a una visión cada vez más meramente económico-técnica del mundo, es decir, en la dirección de una concepción cada vez más servilmente plegada a la efectiva reducción abstracta económica de la vida social no económica (comunitaria) que estaba en efecto teniendo lugar en el mundo" 42 . El sentido de toda la historia pasada y presente de las sociedades humanas se desvela, "en última instancia", a través de un desciframiento puramente económico.

El objeto de la ciencia económica, acompasadamente a este proceso históricocultural que Polanyi está tratando de desvelar, acaba proyectándose a todos los aspectos de la vida humana, quedando de esa manera economizada hasta la última partícula de nuestro quehacer vital. Así lo decía Ludwig non Mises, el gran teórico de la Escuela austriaca: "[...] y deviene, entonces, ciertamente harto difícil trazar neta frontera entre qué acciones deban quedar comprendidas dentro del ámbito de la ciencia económica, en sentido estricto, y cuáles deban ser excluidas, pues la eco-

41 Polanyi, K.: El sustento del hombre, Mondadori, Barcelona, 1994, p. 81.

42 Fuentes Ortega, J. B.: La impostura freudiana, Madrid, Encuentro, 2009, p. 120. 
nomía fue, poco a poco, ampliando sus primitivos horizontes hasta convertirse en una teoría general que abarca ya cualesquiera actuaciones de índole humana. Se ha transformado en praxeología" 43 . Desde el enfoque miseano las leyes que determinan la acción social del moderno capitalismo emanarían de la naturaleza humana misma, como si tales leyes fuesen lo trascendental de toda acción humana posible.

$\mathrm{Y}$, en semejante contexto, el pensamiento económico empieza a cubrir todos los aspectos de la vida social, esto es, la coherencia de lo económico empieza a instalarse de forma imperialista en lo político, en lo educativo, en lo moral, en lo estético. "Siguiendo esta posición debería quedar claro que la importancia de la perspectiva económica [vale decir, economicista] reside precisamente en su capacidad de generar una unidad de motivaciones y valoraciones que llevaría a cabo en la práctica lo preconizado como ideal, es decir, la identidad de mercado y sociedad. Porque sólo si se organiza un estilo de vida que cubra todos los aspectos relevantes, incluyendo las imágenes sobre el hombre y la naturaleza de la sociedad - una filosofía de la vida diaria que comprenda criterios de conducta razonables según el sentido común, una serie de riesgos sensatos, y una moralidad práctica-, se nos ofrecerá ese compendio de doctrinas prácticas y teóricas que por sí solas pueden crear una sociedad o, lo que es lo mismo, transformar una sociedad dada en el período de tiempo de una generación o dos. Y dicha transformación, para mejor o para peor, fue la que hicieron los pioneros de la economía. Es decir, la mentalidad mercantil contenía nada menos que la semilla de una cultura completa - con todas sus posibilidades y limitaciones-, y la imagen del hombre y de una sociedad, transformada en economía de mercado, surgió necesariamente de la estructura esencial de una comunidad humana organizada a través del mercado" 44 . La sociedad de mercado genera una forma de vida y una imagen del mundo; lo que Karl Polanyi tiene delante no es sólo un sistema económico, no es únicamente un determinado modo de producción. Por el contrario, se trata de toda una visión del mundo. La mentalidad mercantil acabó generando una cultura vertebrada, en todos sus ámbitos, por una axiología económica y una filosofía utilitarista ${ }^{4}$.

Todas las instituciones sociales en principio ajenas a lo económico empezaron a quedar organizadas a través de una misma matriz mercantil-utilitaria. "Mientras que las clases sociales estaban directamente determinadas por el mecanismo de

\footnotetext{
43 Mises, L. V.: La acción humana. Tratado de economía, Unión Editorial, Madrid, 1986, p. 361.

44 Polanyi, K.: El sustento del hombre, Barcelona, Mondadori, 1994, p. 82.

45 Aquí no podemos dejar de mencionar a Georg Simmel: entendimiento puramente calculador, economía monetaria, intelectualismo, concepción racionalista del mundo, egoísmo práctico como corolario ineludible de la pura inteligencia estratégica, individualismo, atomización social, utilitarismo moral, la claudicación de toda valoración cualitativa en la determinación objetiva de lo cuantitativo, la preponderancia absoluta del valor de cambio sobre toda otra fuente de valor: todos estos elementos aparecen íntimamente correlacionados en ese magma del espíritu moderno desmenuzado en los trabajos del sociólogo alemán. Véase su clásica obra Filosofía del dinero, Comares, Granada, 2003.
} 
mercado, otras instituciones resultaron afectadas indirectamente. El Estado y el gobierno, el matrimonio y crianza de los hijos, la organización de la ciencia, la educación, la religión y las artes, la elección de profesión, los tipos de vivienda, la forma de los asentamientos, la estética misma de la vida privada, todo tenía que concordar con el modelo utilitario, o al menos no interferir en el funcionamiento del mecanismo de mercado. Pero, puesto que muy pocas actividades humanas pueden realizarse sin nada -hasta un santo necesita su altar-, los efectos inmediatos del sistema de mercado llegaron casi a determinar por completo el conjunto de la sociedad. Fue casi imposible evitar la conclusión de que, así como el hombre «económico» era el hombre «real», el sistema económico era «realmente» la sociedad" 46 . La crítica de Polanyi a esa gran utopía liberal que estimaba como lo más deseable una sociedad enteramente reducida al mecanismo de mercado no se queda, pues, en la mera denuncia de la explotación económica de una clase social a manos de otra. Se trata de una crítica cultural más amplia, de una denuncia de la expansión de lo mercantil y de lo utilitario a todo el conjunto de la vida social; se trata, en suma, de una crítica a la reducción (o determinación) abstracto-económica de la vida humana que se produce en el interior de un mecanismo económico que absorbe dentro de sí todos los lazos sociales y comunitarios, todas las normatividades y ámbitos, todas las tradiciones 47 .

En otras ocasiones Polanyi habla de racionalismo económico: "A la vista de lo anterior, puede dar la impresión de que la Weltanschauung económica contenía en sus dos postulados de racionalismo y atomismo todo lo que era necesario para sentar las bases de una sociedad de mercado. El término eficaz era racionalismo. ¿De qué otro modo podía una sociedad así ser algo más que un conglomerado de átomos comportándose según las reglas de un tipo definido de racionalidad? La acción racional, como tal, es la relación de los fines con los medios; la racionalidad económica, específicamente, supone que los medios son escasos. Pero la sociedad humana va mucho más allá de todo eso. ¿Cuál debería ser el fin del hombre y cómo debería elegir los medios? El racionalismo económico, en el sentido más estricto de la palabra, no tiene respuestas a estas preguntas, que implican motivaciones y valoraciones de un orden moral y práctico que va más allá de la irresistible, y al mismo tiempo vacía, exhortación de su ser «económico». Es así como el vacío se disfrazó de una jerga filosófica ambigua"48. Esa cosmovisión economicista, si así cabe lla-

\footnotetext{
46 Polanyi, K.: El sustento del hombre, Barcelona, Mondadori, 1994, p. 84.

47 Milton Friedman, prócer del neoliberalismo posterior, también lo diría sin ambages: "El amplio uso del mercado reduce la sobrecarga que sufre el entramado social, ya que en todas las actividades que abarca hace innecesaria la conformidad. Cuanto más amplio sea el número de actividades cubiertas por el mercado, menor será el número de cuestiones en las que se requieren decisiones expresamente políticas y, por tanto, en las que es necesario alcanzar un acuerdo". Capitalismo y libertad, Rialp, Madrid, 1966, p. 41.

48 Polanyi, K.: El sustento del hombre, Barcelona, Mondadori, 1994, p. 85.
} 
marla, y a la que polémicamente se enfrenta Polanyi, está organizada por un racionalismo económico que concibe la vida social como un conglomerado de átomos maximizadores de utilidad que funcionan guiados únicamente por esa racionalidad economizadora y utilitaria más allá de la cual nada tiene sentido 49 . En efecto, dentro de esta visión del mundo toda acción humana que no encaje con semejantes parámetros de racionalidad aparecerá inmediatamente como irracional y carente de significado.

Porque el sentido, dentro de esta Weltanschaunng, sólo se adquiere a través de una optimización económica de los medios encaminada a obtener fines que, asimismo, van siendo ellos mismos cada vez más sólo económicos. "La filosofía social fundada sobre tales principios fue tan radical como fantástica. Hacer de la sociedad un conjunto de átomos y de cada individuo un átomo que se comporta según los principios del racionalismo económico, colocaría el total de la existencia humana, con toda su riqueza y profundidad, en el esquema referencial del mercado. Afortunadamente, no puede lograrlo: los individuos tienen personalidades, y la sociedad tiene una historia" 50 . Pero el homo oeconomicus, lejos de ser una mera figura instalada en las extralimitaciones metodológicas de los manuales liberales de ciencia económica, empieza a cobrar existencia histórica; aunque ese "empezar a cobrar existencia", ciertamente, no llegó a culminar, como luego veremos.

La configuración histórica de esa subjetividad económica, tal y como aparece reflejada en los modelos formales de las ciencias económicas, es un proceso íntimamente interrelacionado con la aparición del inédito "campo de lo económico". Por lo tanto, el "espíritu del capitalismo" de Max Weber ${ }^{51}$ y Werner Sombart52 refiere la emergencia de una nueva ética económica, de una nueva subjetividad y de un nuevo continente cognoscitivo, y todos estos componentes quedan aquilatados en una visión del mundo.

Aparece así ensamblado un nomos económico como campo de fuerzas en el que gravitan una moral económica, una determinada racionalidad, una específica subjetividad y una, en definitiva, inédita visión del mundo que se van construyendo de manera retroalimentada y que produce, a la vez como causa y como efecto, diferentes discursos de legitimación entre los cuales se encuentra la teorización de unas ciencias económicas que formalizan, y universalizan, un determinado tipo de

\footnotetext{
49 Sin duda que las tesis formalistas tuvieron su prolongación, por así decir, en las diversas formulaciones de las llamadas "teorías de la elección racional". También estos teóricos postulan una racionalidad de corte formal-maximizador como epítome de la racionalidad humana en general, y comprobamos de nuevo la profunda influencia y pregnancia de los postulados neoclásicos en el desarrollo de todas las ciencias sociales. Véase por ejemplo Gauthier, D.: La moral por acuerdo, Gedisa, Barcelona, 1994.

50 Polanyi, K.: El sustento del hombre, Barcelona, Mondadori, 1994, p. 86.

51 Weber, M.: La ética protestante y el "espíritu” del capitalismo, Alianza, Madrid, 2003, p. 62.

52 Sombart, W.: El burgués, Alianza, Madrid, 1977.
} 
racionalidad y que afianzan, por la vía de la naturalización, un imaginario en el que los parámetros de la sociedad mercantilizada se revisten de autoevidencia y atemporalidad53.

\section{El colapso de la utopía liberal y la "obsoleta mentalidad de mercado"}

Polanyi proponía cuatro pilares que servían de fundamento a la civilización liberal: en primer lugar el sistema de balance del poder que durante un siglo y a través de complejos equilibrios permitió la ausencia de guerras largas y devastadoras entre las grandes potencias. Fue lo que se acabó conociendo como "paz de los cien años". En segundo lugar, el patrón oro internacional. Un tercer pilar, apunta Polanyi, sería la institución de un mercado autorregulado. Y por último, la emergencia del Estado liberal. Este cuadro fue el que fundamentó los lineamientos básicos de la civilización decimonónica. Pero el punto de partida histórico-cultural del que parte toda la reflexión polanyiana es, precisamente, el colapso de dicha civilización.

En los primeros compases de su The Great Transformation podemos leer lo siguiente: "La civilización del siglo XIX se ha derrumbado. Este libro se ocupa de los orígenes políticos y económicos de este evento, y de la gran transformación que inició"54. Estas palabras estaban dichas en 1944. Y esta civilización que había colapsado tan recientemente, cuando Polanyi escribe, encontraba su clave institucional en las leyes de la economía de mercado. "Pero la fuente y la matriz del sistema era el mercado autorregulado. Fue esta innovación la que originó una civilización específica" 55 .

Una de las claves que Polanyi da para poder empezar a comprender semejante acontecimiento es el carácter utópico de la civilización que ahora se hundía. "Nuestra tesis es que la idea de un mercado autorregulado implicaba una utopía total. Tal institución no podría existir durante largo tiempo sin aniquilar la sustancia humana y natural de la sociedad; habría destruido físicamente al hombre y transformado su ambiente en un desierto. Inevitablemente, la sociedad tomó medidas para protegerse, pero todas esas medidas afectaban la autorregulación del mercado, desorganizaban la vida industrial, y así ponían en peligro a la sociedad en otro sentido" 56. Una utopía que no podría terminar de realizarse sin desmembrar con ello la sociedad misma en la que pretendía implantarse; una implantación que de hecho empezó a cristalizar y que, pese a las "reacciones autoprotectoras" desarrolladas por la sociedad contra tal implantación utópica, llevó al orden social a un punto

\footnotetext{
53 Bourdieu, P: Las estructuras sociales de la economía, Manantial, Buenos Aires, 2002.

54 Polanyi, K.: La gran transformación. Fondo de Cultura Económica, México, 2003, p. 49.

55 Ibíd.

56 Ibíd.
} 
límite que, no obstante, terminó con el hundimiento de la civilización del mercado autorregulado.

Friedrich Hayek, desde una óptica diametralmente opuesta, nos habla de un movimiento colectivista que vino a quebrantar esa espontaneidad de la economía de libre mercado, cuando ya ésta por fin se había liberado en su despliegue evolutivo de atávicas servidumbres que la mantenían anquilosada. "Es importante dejar bien sentado esto: el moderno movimiento en favor de la planificación es un movimiento contra la competencia como tal, una nueva bandera bajo la cual se han alistado todos los viejos enemigos de la competencia [...] Lo que en realidad une a los socialistas de la izquierda y la derecha es esta común hostilidad a la competencia y su común deseo de remplazarla por una economía dirigida" 57 . El esquema explicativo de Hayek parte de un sistema de libre competencia aniquilado por lo que él denomina "colectivismo", en sus diferentes manifestaciones de izquierda y de derecha. Polanyi advierte, por el contrario, que la utopía liberal, en todo caso, fue propiciada por la fuerte intervención de los Estados y los poderes públicos, siendo así que, en todo caso, si algunas fuerzas espontáneas hubo no fueron las de la economía de mercado (pues ésta fue producida, insistimos, por la intervención), sino más bien la de todas aquellas fuerzas sociales que se resistieron de uno u otro modo a la creciente integración de un sistema en el que todo empezaba a quedar mercantilizado y en el que todo empezaba a adquirir un precio, incluidos unos hombres y una tierra que eran así producidos para su compraventa. Lo espontáneo fueron, en todo caso, las resistencias de todo tipo (y provenientes de distintos estratos sociales) interpuestas a dicho proceso promovido por los poderes estatales, unas resistencias que existieron ya desde el comienzo de los procesos de cercamientos de los campos ingleses.

Dicho sistema, utópico en su concepción, había ido sin embargo engendrándose institucionalmente a lo largo del siglo XIX: pero nunca llegó a culminar. Y no llegó a culminar por muchos factores, pero hemos de señalar, en primer lugar, que Polanyi tenía claro que se movía en una paradoja, a saber: que esa no-culminación había desembocado de hecho en una catástrofe social de enormes proporciones totalitarias; y que, en cambio, la culminación de la utopía liberal habría conducido, por otras vías, a una catástrofe cultural de igual calibre.

El hundimiento del sistema internacional era un punto de llegada, en cualquier caso, y tal colapso de la civilización del mercado había de rastrearse en la historia social anterior. "Pero si el derrumbe de nuestra civilización surgió con la falla de la economía mundial, ciertamente no fue causado por ella. Sus orígenes se encuentran más de 100 años atrás, en esa marejada social y tecnológica de donde surgió la idea de un mercado autorregulado en Europa occidental" 58 . En los años treinta del siglo

57 Hayek, F. A.: Camino de servidumbre, Alianza, Madrid, 1990, p. 68.

58 Polanyi, K.: La gran transformación. Fondo de Cultura Económica, México, 2003, p. 51. 
$\mathrm{XX}$ asistimos al colapso del sistema internacional y al deslizamiento de Europa hacia nuevas formas post-liberales de organización política y económica. Nos dice Polanyi que sólo entonces, en el fragor de su derrumbe, podemos evaluar y comprender la verdadera naturaleza del proceso civilizatorio en el que habíamos estado embarcados. "Pero el derrumbe del patrón oro apenas fijaba la fecha de un evento demasiado grande para ser causado por él. Nada menos que una destrucción completa de las instituciones nacionales de la sociedad del siglo XIX acompañó a la crisis en gran parte del mundo, y en todas partes se cambiaron y reformaron estas instituciones hasta el punto de quedar casi irreconocibles. El Estado liberal fue reemplazado en muchos países por dictaduras totalitarias, y la institución central del siglo -la producción basada en mercados libres- se vio superada por nuevas formas de economía"59. Y si la sociedad de mercado germinó en primer lugar como fenómeno inglés, fue en el continente donde, quizás, el hundimiento del sistema liberal produjo más dramáticas consecuencias. "A fin de comprender el fascismo alemán, debemos volver a la Inglaterra ricardiana" 60 .

Esa gran transformación por la cual, en los años treinta del siglo XX, toda la civilización liberal decimonónica estalla por los aires, ha de buscarse, en lo que a su genealogía se refiere, en la dinámica social misma de dicha civilización. La culminación de esa crisis bajo la forma totalitaria ha de rastrearse, en su origen mismo, en la dinámica interna del propio orden liberal, y no en patologías irracionales o perturbaciones exógenas al devenir de dicho orden.

Un irracionalismo salvaje no había brotado, intempestivamente, del acervo genético de los habitantes europeos, abrazados a sus banderas en patriótico belicismo expansivo para depredar a sus vecinos. El ser de lo político se convirtió en puro pólemos, como anunciara Carl Schmitt aseverando que lo político se articulaba ontológicamente en una guerra contra el enemigo ${ }^{61}$, pero precisamente como consecuencia del fracaso de la gran utopía liberal, utopía que no condujo a un pacificado bálsamo de naciones comerciantes, como pretendían muchos de los apologetas del liberalismo cuando recurrían a una tradición que hundía sus raíces, en la era moderna, en Montesquieu: "El comercio cura los prejuicios destructivos, y constituye una regla casi general el que dondequiera que hay costumbres sosegadas hay comercio, y dondequiera que hay comercio hay costumbres sosegadas" 62 . Semejante tesis, un preciado axioma de la ideología liberal63, habría de estallar por los aires con las grandes guerras nacidas de la competencia comercial del imperialismo colonial.

\footnotetext{
59 Ibíd. p. 75

60 Ibíd. p. 78

61 Schmitt, C.: El concepto de lo político, Alianza, Madrid, 1998, p. 83.

62 Montesquieu: El espíritu de las leyes, Istmo, Madrid, 2002, p. 430.

63 Véase Schumpeter, J. A.: Imperialismo, clases sociales, Tecnos, Madrid, 1965. p.104. O también Mises, L. V.: La acción humana. Tratado de economía, Unión Editorial, Madrid, 1986. p. 1194.
} 
No fue una presunta "conspiración colectivista" contra los sagrados principios del liberalismo económico, como podría argüir Hayek, lo que condujo a la escalada belicista, sino más bien todo lo contrario; hay que buscar las respuestas en la insostenible situación de tensión nacional e internacional, en los desgarros sociales internos y en el imperialismo colonial y sus guerras comerciales, producidos por la pretensión utópica de extender el mecanismo de mercado autorregulado a escala planetaria, y que condujeron a una situación histórica de no retorno de la que ya conocemos sobradamente sus consecuencias.

Paradójicamente, insiste Polanyi, el origen del cataclismo se halla precisamente en el esfuerzo utópico del liberalismo por reducir todos los resortes sociales, culturales y políticos al funcionamiento autónomo de un sistema económico de libre mercado autorregulado. Esta es la tesis medular de Polanyi, y advierte al respecto: "La afirmación parece extremosa, si no es que estrujante, en su abierto materialismo. Pero la peculiaridad de la civilización cuyo colapso hemos presenciado era precisamente el hecho de que descansaba en fundamentos económicos. Otras sociedades, y también otras civilizaciones, estaban limitadas por las condiciones materiales de su existencia: éste es un rasgo común de toda vida humana [...] Pero la civilización del siglo XIX era económica en un sentido diferente y distintivo [...]"64. El "determinismo económico", tan apestado por Polanyi, estuvo empero muy cerca de cumplirse en una civilización que se cimentó, o pretendió cimentarse, en meros fundamentos económicos. Si la sociedad de mercado era distinta a toda otra sociedad habida en la historia humana era porque, en efecto, quería ser sólo económica ${ }^{65}$.

\section{La vocación práctica del pensamiento polanyiano}

Alfred Marshall, uno de los paladines del pensamiento económico liberal, perteneciente a la escuela neoclásica de economía, aseveraba lo siguiente: "Pudiera esperarse que una ciencia que se ocupa de problemas tan vitales para el bienestar de la Humanidad debiera haber llamado la atención de los mejores pensadores de todas las épocas y que se encontrara ahora en un estado de plena madurez científica. Pero el hecho es que el número de los economistas científicos ha sido siempre muy reducido en proporción con las dificultades del trabajo a realizar, de modo que la ciencia está todavía casi en su estado embrionario. Una de las causas de ello ha sido el hecho de la escasa atención que se ha concedido a la importancia que tiene la Economía para el bienestar de la Humanidad" 66 . Se trata de un texto muy significativo que nos puede servir como perfecta piedra de toque de lo que aquí hemos veni-

\footnotetext{
64 Polanyi, K.: La gran transformación. Fondo de Cultura Económica, México, 2003, p. 77

65 Rosanvallon, P.: El capitalismo utópico, Nueva Visión, Buenos Aires, 2006, p. 6.

66 Marshall, A.: Principios de Economía, Aguilar, Madrid, 1963, p. 5.
} 
do comentando al hilo de la obra de Karl Polanyi pues, en efecto, se sorprende Marshall de que lo económico no haya aparecido hasta época muy reciente como algo que mereciera la atención de los grandes pensadores.

En primer lugar, habría que decir que muchos de "los mejores pensadores de todas las épocas" sí se habían preocupado de todos aquellos asuntos que se vinculan con los aspectos de la organización social que más directamente tienen que ver con esas actividades por medio de las cuales una sociedad humana se reproduce y sobrevive desde un punto de vista material. Lo que ocurre es que esa "preocupación" por dichos asuntos nunca fue una preocupación específica, pues siempre que se pensaba en los "asuntos económicos", que nunca se concebían como tales, aparecían entre medias de otras preocupaciones, teorizaciones y prescripciones de tipo religioso, moral o político. Es decir, el reproche de Marshall es inverosímil y anacrónico, porque la madurez de una "ciencia económica" sólo ha podido darse en una sociedad de un tipo muy específico, la moderna sociedad industrial.

La "atención de los grandes hombres" sólo podía desembocar en un análisis pura y específicamente económico, esto es, un análisis enteramente desprendido de cualquier otra normatividad religiosa, política o moral ${ }^{67}$, sólo podía desembocar en esa especificidad, decimos, cuando dentro del proceso social el aparato tecno-económico empezara a cobrar preponderante autonomía funcional 68 .

El fracaso de la utopía liberal, como ya hemos visto, desembocó en la gran transformación que aupó a los regímenes autoritarios y totalitarios que reaccionaron, de forma criminal, a la locura de una sociedad que estuvo a punto de quedar enteramente sometida a un aparato tecnoeconómico desquiciado. Por ello Polanyi podía decir en 1947 que la mentalidad de mercado había quedado obsoleta69, y Keynes diagnosticar el fin del laissez faire en $1926^{70}$, antes incluso del gran derrumbe del 29. Aunque, bien es verdad, Polanyi no viviría lo suficiente para ver el resurgir furioso de esa "mentalidad de mercado" que, bajo los auspicios del denominado neo-liberalismo, irrumpió en las sociedades de nuestro tiempo con una fuerza renovada.

\footnotetext{
67 Sen, A.: Ética y economía, Madrid, Alianza, 1997.

${ }^{68} \mathrm{La}$ "diferenciación funcional" fue una de las claves de bóveda de una parte muy importante de la teorización sociológica del siglo XX, desde el funcionalismo estructural de Parsons hasta la teoría de sistemas de Luhmann, alumno aventajado de aquél. Un "subsistema económico" diferenciado de los otros sistemas sociales supone una característica específica de las sociedades modernas: sólo podía ser concebida una teorización sociológica semejante en ese preciso contexto histórico, pues nunca antes el proceso económico había aparecido desgajado del resto de relaciones sociales. Véase al respecto Parsons: El sistema de las sociedades modernas, Trillas, México, 1982; o también Luhmann: Complejidad y modernidad: de la unidad a la diferencia, Trotta, Madrid, 1998.

69 Polanyi, K.: "Our obsolete market mentality”, Commentary, no 3, pp. 109-117, 1947.

70 Keynes, J. M.: "The end of laissez-faire”, Hogarth Press, 1926.
} 
Pero más allá de las cuestiones metodológicas, la crítica polanyiana al discurso predominante en las ciencias sociales había de volcarse en una praxis que pudiera, quizás, oponerse a algunos de los más peligrosos efectos producidos por una sociedad que se quiso entregar en cuerpo y alma al mecanismo del mercado. En ese sentido, compartimos también la evaluación que el profesor Carlos Prieto hace de la obra polanyiana: "En la medida en que la ciencia económica (clásica y neoclásica) es la teorización de lo que considera la economía, a pesar de no ser más que la teorización de una economía, la de mercado, y sostiene la inevitabilidad de las leyes que lo conforman, se convierte automáticamente en el instrumento político-ideológico de su defensa y extensión [...] Cualquier crítica de la economía de mercado y cualquier intento de transformación o de reforma del mismo, transformación o reforma que se inscriben claramente en una perspectiva polanyiana, en el sentido de recuperar la preeminencia de la sociedad y de la política sobre la economía, han de pasar así por la crítica de la ciencia económica como tal"71.

Harry W. Pearson, estrecho colaborador, discípulo, recopilador y editor de textos póstumos de Polanyi, explica de esta manera la motivación última que espolea la obra y el pensamiento de éste: "Los objetivos académicos de Polanyi fueron serios y respetables, y siguen motivando a los eruditos de muchos campos, pero el significado profundo y el tema unificador de toda su obra está en la esfera de la filosofía social y política. Diciéndolo de un modo más simple, su preocupación fundamental era que el sistema de mercado occidental había usurpado las funciones específicas y la integridad de la sociedad humana, convirtiendo en supremos los valores económicos y haciendo del hombre y de la naturaleza meros utensilios -forraje para el «molino satánico» del mercado auto-regulador, como él mismo dijo en La gran transformación. La fuerza motora que había detrás de su trabajo era la convicción de que esto no había sido siempre así; que había sido posible producir y distribuir los medios de subsistencia del hombre manteniendo la integridad de la sociedad, y que la historia anterior al mercado ofrecía muchas claves a la posibilidad de devolver el destino del hombre a la variedad de instituciones sociales, políticas y culturales, de la sociedad. Por ello desafió el axioma liberal de que la libertad y la justicia estaban inextricablemente unidas al orden de mercado. Se enfrentó también al determinismo económico, uno de los axiomas básicos de la otra ortodoxia del siglo XIX, el marxismo"72. En todo caso, el recurso a ejemplos tomados de la literatura etnográfica o de la historia antigua, que jalonan la obra polanyiana, no deben interpretarse como contraejemplos rousseaunianos de un Edén perdido a través del progreso de los tiempos; pero tampoco suponen un mero ornamento de erudición. Constituyen, más bien, el modo de quebrar ese imaginario liberal que colapsa toda

\footnotetext{
71 Prieto, C.: "Karl Polanyi: crítica del mercado, crítica de la economía”, Política y Sociedad, № 21, 1996, pp. 23-34.

72 Introducción a El sustento del hombre, Mondadori, Barcelona, 1994, p. 52.
} 
posibilidad de concebir un modo de vida en el que los valores económicos no constituyan una finalidad suprema a la que hayan de estar supeditados y sometidos todos los otros fines de la vida humana. Esa es la motivación profunda que subyace en toda la obra de Polanyi. Él mismo así lo afirma en el prólogo de El sustento del hombre: "[...] la historia debería darnos respuestas para resolver algunos de los problemas morales y prácticos más candentes de nuestra época"73.

Repleta de postulados axiológicos, la teoría económica liberal esconde tras de sí una visión del hombre y una determinada filosofía social y moral74. El corpus teórico de las doctrinas liberales jamás pudo ser, aunque así lo pretendieran, un armazón analítico neutral, pues tras él se escondían prescripciones políticas (cómo debe organizarse la sociedad) y presupuestos psicológicos y antropológicos (cómo es el hombre). En ese sentido, compartimos algunas de las tesis que Gunnar Myrdal propone en su obra El elemento político en el desarrollo de la teoría económica: "Así, la teoría de la «libre competencia» no pretende ser simplemente una explicación científica del rumbo que tomarían las relaciones económicas bajo ciertos supuestos específicos. Tal teoría constituye al propio tiempo una especie de prueba de que estas condiciones hipotéticas darían por resultado la «renta total» máxima o la mayor «satisfacción de necesidades» posible en una sociedad en su conjunto. La «libre competencia» se convierte así, por motivos lógicos y fácticos, en algo más que un conjunto de supuestos abstractos utilizados como instrumento en el análisis teórico de las relaciones causales entre los hechos. Se convierten en un desiderátum político"75. Hemos de retener esta tesis a la hora de ponderar en sus justos términos la obra de Polanyi; una obra que, lejos de quedar encapsulada en los límites internos del discurso académico, acaba mostrando una ineludible vocación práctica.

De este modo, la obra polanyiana supone un potente antídoto, analítico y político-moral, contra esa hybris economicista que ya Aristóteles entreviera en la sociedad de su época, y que se decanta explícitamente con el advenimiento de la moderna sociedad industrial capitalista, para culminar de alguna manera en esta sociedad de consumo que el propio Polanyi no llegó a ver en su fase más desarrollada y paroxística, pero para la cual su análisis aún puede conservar una inestimable potencia crítica76. "Por tanto, es precisamente por la desproporcionada influencia que el sistema de mercado ha ejercido en la sociedad y en nuestra propia experiencia personal, por lo que encontramos difícil comprender el carácter limitado y subordinado de la economía tal y como ésta se presenta fuera de dicho sistema"77. Es esa des-

\footnotetext{
73 Polanyi, K.: El sustento del hombre, Mondadori, Barcelona, 1994, p. 55.

74 Bilbao, A.: “Aristóteles y Smith: la política y la ciencia”, Política y Sociedad, 21 (1996), Universidad Complutense, Madrid (pp.73-87), p. 74.

75 Myrdal, G.: El elemento político en el desarrollo de la teoría económica, Gredos, Madrid, 1967, p. 22.

76 Alba Rico, S.: Las reglas del caos, Anagrama, Barcelona, 1995.

77 Polanyi, K.: El sustento del hombre, Barcelona, Mondadori, 1994, p. 63.
} 
proporción de lo económico dentro de la sociedad capitalista la que nos impide ver o imaginar un afuera de dicho sistema; esa desmesura nos ciega para poder columbrar que lo económico, en otros lugares y en otras épocas, no ocupó un papel tan eminentemente avasallador y totalizador. Y por ello mismo, esa hybris, de no ser desactivada, nos dejará inhabilitados para albergar la esperanza de vivir en una sociedad en la que lo económico no funcione de este modo. Toda la obra de Polanyi consiste, en última instancia, en ese trabajo de desactivación. Y en una época, la nuestra, en la que todo el mundo asume como algo evidente y natural que el poder de "los mercados" sea omnímodo, la obra polanyiana se antoja ineludible para articular una respuesta teórica y práctica al problema más acuciante de nuestro tiempo

\section{Referencias bibliográficas}

Dumont, L.: Homo aequalis. Génesus y apogeo de la ideología económica, Madrid, Taurus, 1999.

Fernández LiRia, C.; Alba Rico, S.: El naufragio del hombre, Hiru, Hondarribia, 2010.

Fernández LiRia, C.; Alegre, L.: El orden de El Capital, Akal, Madrid, 2010.

Friendman, M.: Capitalismo y libertad, Rialp, Madrid, 1966.

Fuentes Ortega, J. B.: La impostura freudiana, Madrid, Encuentro, 2009.

HAYEK, F. A.: Camino de servidumbre, Alianza, Madrid, 1990.

Marshall, A.: Principios de Economía. Aguilar, Madrid, 1963.

Mauss, M.: Sociología y antropología, Tecnos, Madrid, 1991.

Mises, L. V.: La acción humana. Tratado de economía, Unión Editorial, Madrid, 1986.

Montesquieu: El espiritu de las leyes, Istmo, Madrid, 2002.

MYRDAL: El elemento político en el desarrollo de la teoría económica, Gredos, Madrid, 1967.

Polanyi, K.: Comercio y mercado en los imperios antiguos, Barcelona, Labor, 1976.

Polanyi, K.: El sustento del hombre, Barcelona, Mondadori, 1994.

Polanyi, K.: La gran transformación, México, Fondo de Cultura Económica, 2003. Prieto, C.: "Karl Polanyi: crítica del mercado, crítica de la economía", Política y Sociedad, No 21, 1996, pp. 23-34.

Jorge Polo Blanco

Facultad de Filosofía

Universidad Complutense de Madrid

Hiperbolik1983@hotmail.com 